\title{
Effects of Centrally Acting Angiotensin Converting Enzyme Inhibitors on Functional Decline in Patients with Alzheimer's Disease
}

\author{
Rónán O'Caoimh ${ }^{\mathrm{a}, *}$, Liam Healy ${ }^{\mathrm{a}}$, Yang Gao ${ }^{\mathrm{a}}$, Anton Svendrovskib ${ }^{\mathrm{b}}$, David M. Kerins ${ }^{\mathrm{c}, \mathrm{d}}$, \\ Joseph Eustace $^{\mathrm{e}}$, Patrick Gavin Kehoe ${ }^{\mathrm{f}}$, Gordon Guyatt ${ }^{\mathrm{b}}$ and D. William Molloy ${ }^{\mathrm{a}}$ \\ ${ }^{a}$ Centre for Gerontology and Rehabilitation, University College Cork, St Finbarrs Hospital, Cork, Ireland \\ ${ }^{\mathrm{b}}$ Department of Clinical Epidemiology \& Biostatistics, McMaster University, ON, Canada \\ ${ }^{\mathrm{c}}$ Department of Pharmacology and Therapeutics, University College Cork, Cork, Ireland \\ ${ }^{\mathrm{d}}$ Mercy University Hospital, Cork, Ireland \\ ${ }^{\mathrm{e}}$ Clinical Research Facility, Mercy University Hospital, Cork, Ireland \\ ${ }^{\mathrm{f}}$ Dementia Research Group, School of Clinical Sciences, University of Bristol, Frenchay Hospital, Bristol, UK
}

Accepted 10 December 2013

\begin{abstract}
.
Background: Centrally acting angiotensin converting enzyme inhibitors (CACE-Is) are associated with reduced rates of cognitive decline in patients with dementia. CACE-Is may also improve exercise tolerance in functionally impaired older adults with normal cognition, suggesting that CACE-Is may positively influence activities of daily living (ADL) in dementia.

Objective: To compare rates of decline in patients with mild to moderate Alzheimer's disease (AD) receiving CACE-Is to those not currently treated with CACE-Is (NoCACE-I), included in the Doxycycline and Rifampicin for Alzheimer's Disease study $(n=406)$.

Methods: Patients were included if baseline and end-point (twelve months apart) scores were available for measures including the Standardized Alzheimer's Disease Assessment Scale - Cognitive Subscale; Quick Mild Cognitive Impairment screen; Clinical Dementia Rating Scale (CDR-SB), and Lawton-Brody ADL Scale.

Results: There was a significant, 25\% difference (median one-point) in the 12-month rate of decline in ADL scores in patients taking CACE-Is $(n=91)$, compared to the NoCACE-I group $(n=274), p=0.024$. This remained significant after adjusting for age, gender, education, and blood pressure, $p=0.034$. When individual CACE-Is were compared to the NoCACE-I group, a significant reduction in the rate of decline in ADLs (median one versus four points), were only observed for perindopril, $p=0.01$. The CDR-SB was also reduced (median one-point) for the perindopril compared to the NoCACE-I group, $p=0.04$.

Conclusion: This observational study suggests that CACE-Is, and potentially perindopril in particular, are associated with a reduced rate of functional decline in patients with $\mathrm{AD}$, without an association with mood or behavior. This suggests that CACE-Is may slow disease progression in AD.
\end{abstract}

Keywords: ACE inhibitors, Alzheimer's disease, cognitive, dementia, function, psychological decline

\footnotetext{
*Correspondence to: Rónán O’Caoimh, Centre for Gerontology and Rehabilitation, University College Cork, St Finbarrs Hospital, Douglas Road, Cork City, Ireland. Tel.: +353 86 3241795; Fax: +353 21 492309; E-mail: rocaoimh@hotmail.com.
}

\section{INTRODUCTION}

Although higher midlife blood pressure (BP) is associated with increased risk of dementia [1], it is not a simple association [2]. Authors have suggested that a variety of anti-hypertensives improve cognition in 
older adults with elevated BP [3, 4] and have potential as therapeutic agents in dementia [5-11]. Results are however, inconsistent [12-14] with some observational studies even suggesting harm $[15,16]$.

\section{Dementia and angiotensin converting enzyme}

Angiotensin converting enzyme inhibitors (ACE-Is) and angiotensin receptor blockers (ARBs) may lower dementia risk or slow progression independent of their BP lowering properties $[9,10,17,18]$. Centrally acting ACE-Is (CACE-Is), which cross the blood-brain barrier, are associated in observational studies with a reduced incidence of mild cognitive impairment (MCI) $[19,20]$ and dementia [14], and slower rates of cognitive decline in Alzheimer's disease (AD), relative to non-centrally acting ACE-Is [21, 22]. In patients with AD, CACE-Is may modulate the pathological accumulation of amyloid- $\beta(A \beta)$, a key neuropathological hallmark of $\mathrm{AD}$ [23]. ACE gene polymorphisms are associated with increased risk of $\operatorname{AD}[24,25]$ : alleles putatively associated with $\mathrm{AD}$ are also associated with low levels of plasma ACE [26, 27]. Pre-clinical studies suggest that ACE degrades $A \beta$ [28-30], and marked increases in ACE activity have been reported in the frontal cortex of patients with AD [31-33]. More recently, lack of evidence from large scale genetic studies $[5,16]$ has diminished interest in ACE [24] while interest in Angiotensin II, the potent vasoconstrictor formed by ACE action in AD pathology, has increased $[35,36]$.

\section{Centrally-acting ACE-Is and cognition}

The strongest pre-clinical evidence to date for the utility of ACE-Is in affecting cognitive decline is for the CACE-I perindopril. Perindopril reversed A $\beta$ induced cognitive impairment [37], inhibited brain ACE activity, elevating extracellular acetylcholine levels in mice [38], while two non-centrally acting ACE-Is did not. Perindopril, but not other ACE-Is, significantly inhibited hippocampal ACE and prevented cognitive impairment in mouse models of $\mathrm{AD}$ [39, 40, 41]. Clinically, the Cardiovascular Health Study reported observational data that perindopril, rather than noncentrally acting ACE-Is or calcium channel blockers, decreased the rate of decline in patients with mild to moderate AD [14]. Results, however, are inconsistent. Secondary analysis of randomized trials have failed to detect an effect of ACE-Is [42] or ARBs on cognition $[12,43]$. Furthermore, a small placebo controlled clinical trial in non-demented offspring of AD patients showed no effect on cognition [44].

\section{Effects of CACE-Is on ADLs and the behavioral and psychological symptoms of dementia (BPSD)}

Observational studies suggest that beta-blockers are associated with reduced rates of functional decline in patients with established AD [45]. Although, there is no association for ACE-Is [14, 45], they are associated with increased exercise tolerance, muscle strength [46], and lower falls risk [46, 47], suggesting effects independent of their BP lowering properties. Furthermore, the discontinuation of ACE-Is in those with $\mathrm{AD}$ is associated with increased rates of functional decline [48]. Studies investigating ACE genotypes in functional decline suggest both increased [49] and decreased disability [50]. There is also evidence that ACE-Is modulate mood, including anxiety [51] and depression in hypertensive patients with normal cognition [52]. Again, evidence is inconsistent [53, 54].

\section{Objective}

The aim of this paper was to compare rates of cognitive, functional, and neuropsychological decline in patients with $\mathrm{AD}$ receiving CACE-Is (called CACE-Is) to those not currently treated with CACE-Is (NoCACEI) by conducting a secondary analysis of data from a randomized control trial.

\section{METHODS}

\section{Data collection}

We performed a secondary analysis of data from the Doxycycline and Rifampin for Alzheimer's Disease (DARAD) trial [55], a multi-center, blinded, randomized $2 \times 2$ factorial controlled trial, conducted between 2006 and 2010, comparing two antibiotics (doxycycline and rifampicin) to placebo, to investigate if these can delay progression of $\mathrm{AD}$ [55]. The co-primary outcomes were the Standardized Alzheimer's Disease Assessment Scale-Cognitive Subscale (SADAS-cog) [56] and the Clinical Dementia Rating scale-Sum of the Boxes (CDR-SB) [57]. Secondary outcomes included the Standardized Mini-Mental State Examination (SMMSE) [58, 59], Quick Mild Cognitive Impairment screen (Qmci) [60-62], the Geriatric Depression Scale (GDS) [63], Cornell Scale for Depression in Dementia (CSDD) [64], Lawton-Brody ADL Scale [65], and the Dysfunctional Behaviour Rating Instrument (DBRI), 
frequency (DBRIF) and reaction (DBRIR), subscales $[66,67]$. The SADAS-cog, CDR-SB, Qmci, LawtonBrody ADL Scale, and DBRI were available at one, three, six, nine, and twelve months (end-point). The SMMSE was recorded at screening and end-point, the GDS at baseline and end-point and the CSDD at baseline, six-months and end-point only.

The SADAS-cog is a standardized version of the ADAS-cog [68], the existing, accepted standard for measuring cognitive function in clinical trials [69]. Consisting of 11 domains (including word recall, object naming, command following, construction, orientation, word recognition, language, speech comprehension, word finding and recall), the SADAS-cog improved inter-rater reliability using explicit administration and scoring guidelines. Scored from 0-70, scores $\geq 13$ indicate increasing cognitive impairment [56]. The CDR-SB, a measure of global function, is scored from $0-18$ with a score of 0 indicating no impairment, 0.5-4.0 possible impairment, and 4.5-9.0, 9.5-15.5, and 16.0-18.0 suggesting mild, moderate, and severe impairment, respectively [57]. The Qmci screen is a short (3-5 min), cognitive screening instrument composed of six subtests, covering five domains: orientation, registration, clock drawing, delayed recall, verbal fluency (naming animals) and logical memory (immediate verbal recall of a short story), scored out of 100 points. It has superior accuracy for detecting MCI compared to the SMMSE [60] and similar accuracy as the Montreal Cognitive Assessment (O'Caoimh 2013 unpublished work). The Lawton-Brody ADL Scale, combining both basic (Physical Self-Maintenance Scale) and instrumental ADLs, covering 14 categories, is scored out of 64 points, with higher scores suggesting greater independence [65]. The GDS short-form is scored from $0-15$ with a score $\geq 5$ suggesting depression $[63,70]$. The CSDD is a 19-item scale, range of 0-39: normal $<6$, probable depression 10-17, definite depression $\geq 18$. The DBRI, completed by caregivers, scores the frequency of (from 'never' to 'greater than five times per day') and reaction to (impact from 'no problem' to 'great deal of a problem') 25 behaviors [66].

\section{Participants}

In total, 406 patients with mild to moderate AD (SMMSE scores between 14 and 26) were included from 14 geriatric outpatient clinics in Canada [55]. All patients were aged 50 years or more and met the National Institute of Neurological Disorders and Stroke (NINCDS) criteria for AD [71]. In this study, patients were subdivided into a CACE-I group, including patients currently prescribed centrally acting ACE-Is: ramipril $(n=57)$, perindopril $(n=21)$, lisinopril $(n=9)$, trandolapril $(n=3)$, and fosinopril $(n=1)$ $[14,19]$, and a NoCACE-I group not currently receiving CACE-Is, irrespective of BP readings, diagnosis of hypertension, or receipt of other anti-hypertensives.

\section{Analysis}

The average 12-month rate of change in outcomes, measured as the difference between baseline and 12-month scores, were compared between patients receiving CACE-Is and the NoCACE-I group. For the Qmci, CSDD, GDS, and Lawton-Brody ADL Scale, change was calculated as the baseline minus the 12month score. The SADAS-cog, CDR-SB, DBRIF, and DBRIR scales were calculated as the score at month 12 minus the baseline. In this way, irrespective of the scoring instructions, positive change denoted improvement. The SMMSE, used as an inclusion criterion, was not used in the analysis. Data were analyzed using SPSS 20.0. Non-normally distributed numerical data were compared using the independent samples median test, while chi-square tests were used for categorical data. Multivariate regression analysis was used to compare baseline measurement scores, adjusted for baseline characteristics; age, years of education, and BP (systolic and diastolic), between the CACE-I and NoCACE-I groups and CACE-I subgroups: perindopril and other CACE-Is. Multivariate regression was also used to compare the rate of decline, in each measure, between the subgroups.

\section{RESULTS}

\section{Baseline demographics}

Co-primary outcome measures were available for 365 patients at 12 months; for most, secondary outcomes were also available. The remaining 41 patients were lost to follow-up because of death $(n=13)$, refusal $(n=14)$, adverse events $(n=6)$, withdrawal from the trial $(n=5)$, and other reasons (moved, caregiver death, $n=3$ ). Table 1 presents patients' baseline characteristics. Of the 365 patients included, 91 were taking CACE-Is during the course of the trial: 21 receiving perindopril and 70 other CACE-Is (Figure 1). Although no difference in baseline outcome measure scores were present between the CACE-I and NoCACE-I groups, when the CACE-I subgroups (perindopril and other CACE-Is) were compared to the NoCACE-I group, 
Table 1

Differences in baseline demographic characteristics and outcome measures of patients receiving centrally acting ACE inhibitors (CACE-I) to those not currently treated with CACE-Is (NoCACE-I)

\begin{tabular}{|c|c|c|c|c|c|c|}
\hline & $\begin{array}{c}\text { CACE } \\
(n=91) \\
\text { Median (IQR) }\end{array}$ & $\begin{array}{c}\text { NoCACE } \\
(n=274) \\
\text { Median (IQR) }\end{array}$ & $\begin{array}{c}\text { Perindopril } \\
(n=21) \\
\text { Median (IQR) }\end{array}$ & $\begin{array}{l}\text { Other CACE-Is } \\
\quad(n=70) \\
\text { Median (IQR) }\end{array}$ & $p$-value ${ }^{1}$ & $\overline{p-\text { value }^{2}}$ \\
\hline Age & $79(8)$ & $78(10)$ & $78(9)$ & $79(10)$ & 0.90 & 0.72 \\
\hline Gender (male \%) & $45.1 \%$ & $51.1 \%$ & $23.8 \%$ & $51.4 \%$ & 0.46 & 0.05 \\
\hline Education (years) & $12(4)$ & $12(5)$ & $12(5)$ & $12(3.5)$ & 0.06 & 0.15 \\
\hline Blood pressure systolic & $138(19)$ & $134(22.5)$ & $140(19)$ & $135.5(17.25)$ & 0.41 & 0.45 \\
\hline Blood pressure diastolic & $70(14)$ & $72(14)$ & $70(11)$ & $70(12.5)$ & 0.41 & 0.66 \\
\hline Cholinesterase inhibitor use (\%) & $89.0 \%$ & $92.3 \%$ & $76.2 \%$ & $92.9 \%$ & 0.32 & 0.03 \\
\hline Memantine use $(\%)$ & $15.4 \%$ & $15.3 \%$ & $14.2 \%$ & $15.7 \%$ & 0.64 & 0.99 \\
\hline SMMSE & $23(4.5)$ & $22.5(5)$ & $24(2)$ & $23(5)$ & 0.14 & 0.22 \\
\hline Qmci & $39.5(18)$ & 39 (19) & $40(12)$ & $39(20)$ & 0.74 & 0.90 \\
\hline SADAS-cog & $18(12)$ & $21(11)$ & $16(9)$ & $19(12)$ & 0.05 & 0.04 \\
\hline Lawton-Brody ADL & $51(10)$ & $52(10)$ & $52(9)$ & $51(11)$ & 0.34 & 0.57 \\
\hline CDR-SB & $5(4)$ & $5(4)$ & $4.5(4)$ & $6(4)$ & 0.74 & 0.23 \\
\hline CSDD & $3(5)$ & $3(4)$ & $4(8)$ & $3(5)$ & 0.09 & 0.23 \\
\hline GDS & $1(2)$ & $1(3)$ & $2(2)$ & $1(2)$ & 0.74 & 0.82 \\
\hline DBRIF & $4(13)$ & $5(10)$ & $3(11)$ & $4(13)$ & 0.61 & 0.88 \\
\hline DBRIR & $11(12)$ & $13(11)$ & $12(16)$ & $11(12)$ & 0.45 & 0.75 \\
\hline
\end{tabular}

${ }^{1} p$-values are provided for independent samples median test (numerical data) or Chi-square test (categorical data) for comparison between CACEI and NoCACE-I groups; ${ }^{2} p$-values are provided for independent samples median test (numerical data) or Chi-square test (categorical data) for comparison between perindopril, other CACE-Is and NoCACE-I groups; ADL, activities of daily living; CDR-SB, Clinical Dementia Rating scale-Sum of the Boxes; CSDD, Cornell Scale for Depression in Dementia; DBRIF, Dysfunctional Behaviour Rating Instrument-frequency; DBRIR, Dysfunctional Behaviour Rating Instrument-reaction; GDS, Geriatric Depression Scale; IQR, interquartile range; Qmci, Quick Mild Cognitive Impairment screen; SADAS-cog, Standardized Alzheimer's Disease Assessment Scale-Cognitive Subscale; SMMSE, Standardized Mini-Mental State Examination.

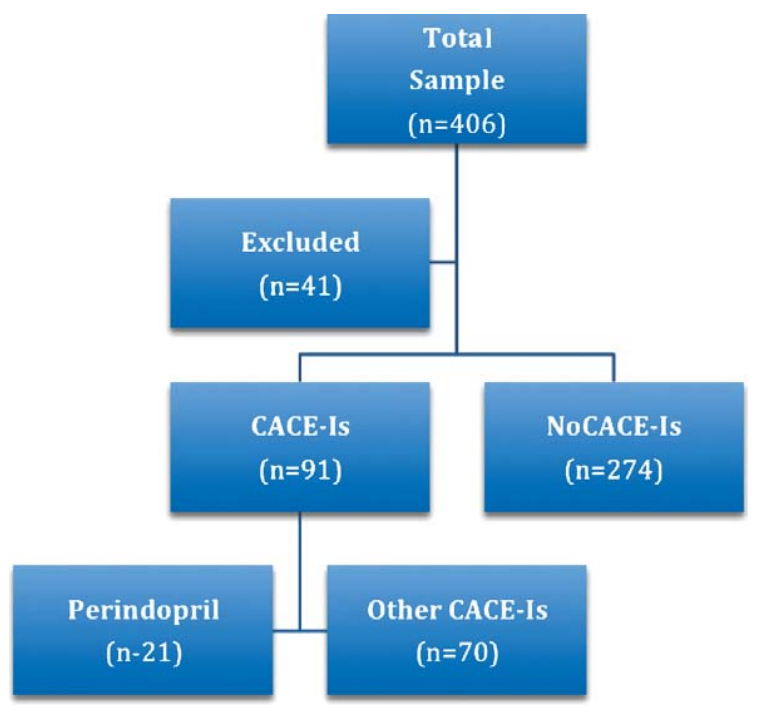

Fig. 1. Flow diagram demonstrating the breakdown of the patients included from the Doxycycline and Rifampin for Alzheimer's Disease (DARAD) trial database receiving centrally acting ACE inhibitors (CACE-Is: perindopril and others) and those not currently treated with CACE-Is (NoCACE-I).

there was a marginal statistically significant difference in baseline characteristics for gender $(p=0.05)$, cholinesterase inhibitor use $(p=0.03)$, and SADAScog scores $(p=0.04)$ (Table 2$)$.
Table 2

Comparison of the rate of decline, from baseline to one year, between patients receiving centrally acting ACE inhibitors (CACE-I) and those not currently treated with CACE-Is (NoCACE-I)

\begin{tabular}{llcll}
\hline Variable & $\begin{array}{c}\text { CACE-I } \\
\text { Median } \\
(\mathrm{IQR})\end{array}$ & $\begin{array}{c}\text { NoCACE-I } \\
\text { Median } \\
(\mathrm{IQR})\end{array}$ & $p$-value & \\
\hline Blood pressure systolic & $0(30)$ & $1.5(24)$ & 0.38 & 0.6 palue $^{2}$ \\
Blood pressure diastolic & $0(20)$ & $0(18)$ & 0.69 & $0.71^{*}$ \\
SADAS-cog & $2(9)$ & $4(8)$ & 0.41 & 0.86 \\
CDR-SB & $2(4)$ & $1.5(3.5)$ & 0.83 & 0.84 \\
Qmci & $4(12)$ & $5(13)$ & 0.15 & 0.49 \\
Lawton-Brody (ADL) & $3(6)$ & $4(7)$ & 0.024 & 0.034 \\
CSDD & $0(3)$ & $1(4)$ & 0.13 & 0.001 \\
GDS & $0(2)$ & $0(2)$ & 0.95 & 0.94 \\
DBRIF & $0(9)$ & $0(8)$ & 0.50 & 0.24 \\
DBRIR & $4(13)$ & $2(11)$ & 0.50 & 0.44 \\
\hline
\end{tabular}

${ }^{1} p$-values are provided for unadjusted comparisons between CACE-I and NoCACE-I groups; ${ }^{2} p$-values are provided for multivariate regression (adjusted for age, gender, education, and blood pressure) for comparison between the CACE-I and NoCACE-I groups; *Adjusted for age, gender, and education; ADL, activities of daily living; CDR-SB, Clinical Dementia Rating scale-Sum of the Boxes; CSDD, Cornell Scale for Depression in Dementia; DBRIF, Dysfunctional Behaviour Rating Instrument-frequency; DBRIR, Dysfunctional Behaviour Rating Instrument-reaction; GDS, Geriatric Depression Scale; IQR, interquartile range; Qmci, Quick Mild Cognitive Impairment screen; SADAS-cog, Standardized Alzheimer's Disease Assessment Scale-Cognitive Subscale. 


\section{Rate of decline}

Patients receiving CACE-Is had a median decline of three points (IQR six) in ADL scores between baseline and 12 months, in comparison to a decline of four points (IQR seven) in the NoCACE-I group $(p=0.024)$. No statistically significant differences in decline were evident for the other outcome measures in the unadjusted analysis. However, patients taking CACE-Is demonstrated a median decline in Qmci screen scores of four (IQR 12) versus five (IQR 13) points in the NoCACE-I group $(p=0.15)$. The deterioration in CDR-SB and CSDD scores was also less marked in the CACE-I group relative to the NoCACE-I group, although again differences were not statistically significant (Table 2). Adjusting for age, education, gender, and BP confirmed a significant difference in ADL scores $(p=0.034)$. The adjusted analysis also showed a significant one point difference in the rate of decline between groups in the CSDD scores $(p=0.001$, Table 2$)$ : $57 \%(n=52)$ of CACEI improved or remained the same, compared to $47 \%$ $(n=128)$ in the NoCACE-I group.

When individual CACE-Is were compared to the NoCACE-I group, a significant median reduction in the rate of decline in ADLs, one point compared to four points, was observed for those receiving perindopril $(p=0.01)$. The CDR-SB was also reduced by a median of one point $(p=0.04)$ for the perindopril compared to the NoCACE-I group. Median decline in CDR-SB scores was 0.5 (IQR 3 ) in patients receiving perindopril versus 2.5 (IQR 4) in those receiving other CACE-Is $(p=0.05)$. Patients receiving other CACE-Is showed a median decline in ADL scores of three points (IQR seven), compared to one point (IQR six) for perindopril $(p=0.09)$. Patients reported few adverse events that could possibly be related to ACE-I treatment. Of those taking CACE-Is, six noted a fall, while none reported cough or orthostatic symptoms.

\section{DISCUSSION}

This study found a small (25\%, three versus four points) reduction in the rate of decline in $\mathrm{ADL}$ scores, measured with the Lawton-Brody ADL Scale, over a 12-month period, in patients taking CACE-Is compared to those not currently receiving CACE-Is. Other outcomes measures were also associated with a decreased progression for the CACE-I compared to the NoCACE-I group, although only changes in ADL and CSSD scores were statistically significant. In particular, the Qmci screen scores declined 20\% less (four versus five points respectively), for the CACE-I group over one year, not inconsistent with other studies demonstrating a slower rate of cognitive decline in persons with dementia receiving CACE-Is [21, 22, 72].

Investigators have not previously reported a reduced rate of decline in ADLs in patients with established dementia receiving CACE-Is, although the effect has been shown with beta-blockers [45]. Since we found no significant changes in BP over the 12-month followup period, these benefits are likely to be independent of an anti-hypertensive effect. There are a number of possible mechanisms by which CACE-Is could impact upon ADLs. Perindopril improves exercise tolerance in older adults with normal cognition, with [73] and without heart failure [46]. This might be explained by the reported ability of ACE-Is to reduce inflammation and to improve endothelial function, increasing muscle blood flow and glucose delivery [74] to both skeletal and cardiac muscle, thereby improving exercise tolerance and capacity. Previous trials have demonstrated benefits, equivalent to six months of training, with four weeks exposure to ACE-Is [46]. These effects appear to be unique to ACE-Is, when compared to other classes of anti-hypertensives [75], further supporting that the benefits are independent of the drugs BP lowering properties. In addition, individuals with polymorphisms, resulting in low ACE activity, have an enhanced response to training [76] although this contrasts with the observations of increased ADL disability for the same gene variants in older populations [49]. The association between treatment with either ACE-Is and/or ARBs, with a lower incidence of falls also supports the theory that these medications may produce global effects on physical function [47]. Therefore, one year of ACE-I treatment could, theoretically, result in improvements in muscle strength and function, sufficient to alter the rate of decline in ADLs.

Other studies, however, contradict these findings. Results from the Cardiovascular Health Study, investigating incidence of dementia, suggest that exposure to ACE-Is and non-CACE-Is in particular, are associated with an increased dependency in ADLs [14]. Although these reductions may have been relative to smaller disimprovements with other anti-hypertensives, such as calcium channel blockers, which are also associated with reduced incidence of dementia [77, 78] and possibly reduced progression that is currently being tested in clinical trials [Nilvad registered trial EudraCT Number: 2012-002764-27]. The TRAIN study demonstrated no benefit in muscle strength or 
exercise performance for fosinopril over placebo in patients with high cardiovascular risk but normal cognition [79].

In this study, the use of perindopril was associated with a slower rate of decline in measures of cognition (SADAS-cog and Q $m c i$ ), global function (CDR-SB), and ADLs compared to other CACE-Is, although only the CDR-SB reached statistical significance. The potential benefits of perindopril on exercise tolerance over other ACE-Is has been commented upon previously [79], with most studies reporting positive findings using perindopril $[46,73,79]$ and negative findings using other agents such as fosinopril [79] or quinapril [81].

The results presented here also suggest that depressive symptoms (measured using the CSDD) were more likely to improve or remain unchanged in patients receiving CACE-Is. Although reductions in the adjusted one-year rate of decline were statistically significant for the CSDD, between the CACE-I and NoCACE-I groups, the effects were small (both had a median three-point change over the year, see Table 2). The frequency of the BPSD, as measured by the DBRIF and DBRIR, reduced for both CACE-I and NoCACE-I groups, although this did not achieve statistical significance. Thus, minimal or no effects of CACE-Is on mood or the BPSD were demonstrated in this study. Both the CACE-I and NoCACE-I groups appeared to demonstrate little difference in rates of decline in their GDS, CSDD, and DBRI scores over the year of follow-up. Although more patients in the CACEI group compared to the NoCACE-I group showed a significant improvement in CSDD scores (57\% versus $47 \%$ ) over one year, CSDD scores were significantly higher in the CACE-I group at baseline. These data support the current evidence that ACE-Is, in general, have little effect on mood and depression [53, 54].

Strengths of our study include that the data were collected as part of a clinical trial, with rigorous interviewer training and quality checks. Furthermore, the DARAD trial had a relatively low loss to follow-up and good compliance with measurements throughout [55]. Other strengths include the large numbers, regular assessment, and measurement of a wide variety of outcomes over one year [55]. Limitations to this study included the fact that patients had established dementia, median SMMSE of 23, and may have been taking CACE-Is for many years. Another limitation is that as this was an observational study, derived from the secondary analyses of data from a randomized control trial; it was not possible to identify duration or previous history of anti-hypertensive treatment. Furthermore, compliance with anti-hypertensive medications, which has been shown to reduce with time, may also have been a confounder [82, 83]. A percentage of patients in the NoCACE-I group (41\%) were not receiving any anti-hypertensive treatment. By lowering BP, which is associated with progression of cognitive and functional impairment [45], these medications may have caused bias from confounding by indication favoring those currently receiving them. However, baseline characteristics including BP were similar between the CACE-I and NoCACE-I groups and were not associated with rates of decline. Likewise, most anti-hypertensive drugs have been linked with reduced rates of cognitive and or functional decline $[9,10,14,17,18,45]$. There were marginal differences of borderline significance between the three groups (CACE-I, NoCACE-I, and perindopril) in gender, cholinesterase inhibitor use, and SADAS-cog scores. However, the difference in deterioration in ADLs remained after adjustment for these variables. The marker of ADLs used, the LawtonBrody ADL Scale score, is not a gold standard outcome measure, but it is still a widely used instrument that incorporates both instrumental and basic activities of daily living [14, 65, 84]. Indeed, like most instruments measuring ADLs, it is subject to potential bias arising from self or informant reporting rather than a demonstration of ability, and insensitivity to small changes in function. Another limitation and perhaps most important, is that inferences regarding treatment effects are limited by the small effects, the borderline significance of the findings, and the multiple comparisons increasing the likelihood of chance findings. Small effects may however also reflect that this analysis was conducted in patients with more advanced disease. Therefore greater effects may be gained from longer treatment periods in patients with less advanced pathology or people with early stages of cognitive impairment (e.g., MCI), where cognitive benefits have previously been reported $[19,20]$.

Overall, this study suggests the possibility of benefit for patients with established AD taking CACE-Is compared to a group not currently treated with CACEIs, across a range of outcome measures, particularly ADLs. The finding of a reduced rate of progression in ADL disability is small and if real of uncertain significance and with an unclear mechanism. Nevertheless, if such an effect were sustained over years, patient-important benefit may result. Our data provide modest support for the hypothesis that CACE-Is, and perhaps perindopril in particular, may slow disease progression in patients with dementia. At present no anti-hypertensive agents have been licensed for the 
treatment of AD. These data support the need for further study.

\section{ACKNOWLEDGMENTS}

Funding for this study is from Atlantic Philanthropy, and the Canadian Institute of Health Research (CIHR).

Authors' disclosures available online (http://www.jalz.com/disclosures/view.php?id=2056).

\section{REFERENCES}

[1] Whitmer RA, Sidney S, Selby J, Johnston SC, Yaffe K (2005) Midlife cardiovascular risk factors and risk of dementia in late life. Neurology 64, 277-281.

[2] Joas E, Backman K, Gustafson D, Ostling S, Waern M, Guo $\mathrm{X}$, Skoog I (2012) Blood pressure trajectories from midlife to late life in relation to dementia in women followed for 37 years. Hypertension 59, 796-801.

[3] Fogari R, Mugellini A, Zoppi A, Derosa G, Pasotti C, Fogari E, Preti P (2003) Influence of losartan and atenolol on memory function in very elderly hypertensive patients. J Hum Hypertens 17, 781-785.

[4] Fogari R, Mugellini A, Zoppi A, Marasi G, Pasotti C, Poletti L, Rinaldi A, Preti P (2004) Effects of valsartan compared with enalapril on blood pressure and cognitive function in elderly patients with essential hypertension. Eur J Clin Pharmacol 59, 863-868.

[5] Kehoe PG, Passmore PA (2012) The renin-angiotensin system and antihypertensive drugs in Alzheimer's disease: current standing of the angiotensin hypothesis? J Alzheimers Dis $\mathbf{3 0}$, 251-268.

[6] Fournier A, Oprisiu-Fournier R, Serot JM, Godefroy O, Achard JM, Faure S, Mazouz H, Temmar M, Albu A, Bordet R, Hanon O, Gueyffier F, Wang J, Black S, Sato N (2009) Prevention of dementia by antihypertensive drugs: how AT1-receptor-blockers and dihydropyridines better prevent dementia in hypertensive patients than thiazides and ACEinhibitors. Expert Rev Neurother 9, 1413-1431.

[7] Goodison WV, Frisardi V, Kehoe PG (2012) Calcium channel blockers and Alzheimer's disease: potential relevance in treatment strategies of metabolic syndrome. J Alzheimers Dis 30, 269-282.

[8] Khachaturian AS, Zandi PP, Lyketsos CG, Hayden KM, Skoog I, Norton MC, Tschanz JT, Mayer LS, Welsh-Bohmer KA, Breitner JC (2006) Antihypertensive medication use and incident Alzheimer disease: The Cache County Study. Arch Neurol 63, 686-692.

[9] Davies NM, Kehoe PG, Ben-Shlomo Y, Martin RM (2011) Associations of anti-hypertensive treatments with Alzheimer's disease, vascular dementia, and other dementias. J Alzheimers Dis 26, 699-708.

[10] Li NC, Lee A, Whitmer RA, Kivipelto M, Lawler E, Kazis LE, Wolozin B (2010) Use of angiotensin receptor blockers and risk of dementia in a predominantly male population: prospective cohort analysis. BMJ 340, b5465.

[11] Ohrui T, Matsui T, Yamaya M, Arai H, Ebihara S, Maruyama M, Sasaki H (2004) Angiotensin-converting enzyme inhibitors and incidence of Alzheimer's disease in Japan. J Am Geriatr Soc 52, 649-650.
[12] Staessen JA, Thijs L, Richart T, Odili AN, Birkenhager WH (2011) Placebo-controlled trials of blood pressure-lowering therapies for primary prevention of dementia. Hypertension 57, e6-e7.

[13] Poon IO (2008) Effects of antihypertensive drug treatment on the risk of dementia and cognitive impairment. Pharmacotherapy $\mathbf{2 8}, 366-375$.

[14] Sink KM, Leng X, Williamson J, Kritchevsky SB, Yaffe K, Kuller L, Yasar S, Atkinson H, Robbins M, Psaty B, Goff DC Jr (2009) Angiotensin-converting enzyme inhibitors and cognitive decline in older adults with hypertension: results from the Cardiovascular Health Study. Arch Intern Med 169, 1195-1202.

[15] Kehoe PG, Davies NM, Martin RM, Ben-Shlomo Y (2013) Associations of angiotensin targeting antihypertensive drugs with mortality and hospitalization in primary care patients with dementia. J Alzheimers Dis 33, 999-1008.

[16] Kehoe P, Miners S, Love S (2009) Angiotensins in Alzheimer's disease-friend or foe? Trends Neurosci 32, 619628.

[17] Hajjar I, Hart M, Milberg W, Novak V, Lipstz L (2009) The rationale and design of the antihypertensives and vascular, endothelial, and cognitive function (AVEC) trial in elderly hypertensives with early cognitive impairment: Role of the renin angiotensin system inhibition. BMC Geriatr 9, 48.

[18] Hajjar I, Hart M, Chen Y, Mack W, Milberg W, Chui H, Lipsitz L (2012) Effect of antihypertensive therapy on cognitive function in early executive cognitive impairment: A Double-Blind Randomized Clinical Trial. Arch Intern Med 172, 442-444.

[19] Solfrizzi V, Scafato E, Frisardi V, Seripa D, Logroscino G, Kehoe PG, Imbimbo BP, Baldereschi M, Crepaldi G, Di Carlo A, Galluzzo L, Gandin C, Inzitari D, Maggi S, Pilotto A, Panza F; Italian. Longitudinal Study on Aging Working Group (2013) Angiotensin-converting enzyme inhibitors and incidence of mild cognitive impairment. The Italian Longitudinal Study on Aging. Age (Dordr) 35, 441-453.

[20] Rozzini L, Chilovi BV, Bertoletti E, Conti M, Del Rio I, Trabucchi M, Padovani A (2006) Angiotensin converting enzyme (ACE) inhibitors modulate the rate of progression of amnestic mild cognitive impairment. Int J Geriatr Psychiatry 21, 550-555.

[21] Ohrui T, Tomita N, Sato-Nakagawa T, Matsui T, Maruyama M, Niwa K, Arai H, Sasaki H (2004) Effects of brainpenetrating ACE inhibitors on Alzheimer disease progression. Neurology 63, 1324-1325.

[22] Gao Y, O'Caoimh R, Healy L, Kerins D, Guyatt G, Eustace J, Sammon D, Molloy DW (2013) Effects of centrally acting angiotensin converting enzyme inhibitors on the rate of cognitive decline in dementia. BMJ Open 3, e002881.

[23] Hardy J (2009) The amyloid hypothesis for Alzheimer's disease: a critical reappraisal. J Neurochem 110, 1129-1134.

[24] Kehoe PG, Russ C, McIlory S, Williams H, Holmans P, Holmes C, Liolitsa D, Vahidassr D, Powell J, McGleenon B, Liddell M, Plomin R, Dynan K, Williams N, Neal J, Cairns NJ, Wilcock G, Passmore P, Lovestone S, Williams J, Owen MJ (1999) Variation in DCP1, encoding ACE, is associated with susceptibility to Alzheimer disease. Nat Genet 21, 71-72.

[25] Lehmann DJ, Cortina-Borja M, Warden DR, Smith AD, Sleegers K, Prince van Duijn CM, Kehoe PG (2005) Large meta-analysis establishes the ACE insertion-deletion polymorphism as a marker of Alzheimer's disease. Am J Epidemiol 162, 305-317.

[26] Rigat B, Hubert C, Alhenc-Gelas F, Cambien F, Corvol P, Soubrier F (1990) An insertion/deletion polymorphism in the angiotensin I-converting enzyme gene accounting for half the 
variance of serum enzyme levels. J Clin Invest 86, 13431346.

[27] Tiret L, Rigat B, Visvikis S, Breda C, Corvol P, Cambien F, Soubrier F (1992) Evidence, from combined segregation and linkage analysis, that a variant of the angiotensin I-converting enzyme (ACE) gene controls plasma ACE levels. Am J Hum Genet 51, 197-205.

[28] Hemming ML, Selkoe DJ (2005) Amyloid beta -protein is degraded by cellular angiotensin-converting enzyme (ACE) and elevated by an ACE inhibitor. J Biol Chem 280, 3764437650.

[29] Hu J, Igarashi A, Kamata M, Nakagawa H (2001) Angiotensin-converting enzyme degrades Alzheimer amyloid beta-peptide (A beta); retards A beta aggregation, deposition, fibril formation; and inhibits cytotoxicity. J Biol Chem 276, 47863-47868.

[30] Oba R, Igarashi A, Kamata M, Nagata K, Takano S, Nakagawa H (2005) The N-terminal active centre of human angiotensin-converting enzyme degrades Alzheimer amyloid beta-peptide. Eur J Neurosci 21, 733-740.

[31] Miners JS, Ashby E, Van Helmond Z, Chalmers KA, Palmer LE, Love S, Kehoe PG (2008) Angiotensin-converting enzyme (ACE) levels and activity in Alzheimer's disease, and relationship of perivascular ACE-1 to cerebral amyloid angiopathy. Neuropathol Appl Neurobiol 34, 181-193.

[32] Miners S, Ashby E, Baig S, Harrison R, Tayler H, Speedy E, Prince JA, Love S, Kehoe PG (2009) Angiotensin-converting enzyme levels and activity in Alzheimer's disease: differences in brain and CSF ACE and association with ACE1 genotypes. Am J Transl Res 1, 163-177.

[33] Miners JS, van Helmond Z, Raiker M, Love S, Kehoe PG (2010) ACE variants and association with brain Abeta levels in Alzheimer's disease. Am J Transl Res 3, 73-80.

[34] Belbin O, Brown K, Shi H, Medway C, Abraham R, Passmore P, Mann D, Smith AD, Holmes C, McGuiness B, Craig D, Warden D, Heun R, Kölsch H, Love S, Kalsheker N, Williams J, Owen MJ, Carrasquillo M, Younkin S, Morgan K, Kehoe PG (2011) A multi-center study of ACE and the risk of late-onset Alzheimer's disease. J Alzheimers Dis 24, 587-597.

[35] Tian M, Zhu D, Xie W, Shi J (2012) Central angiotensin II-induced Alzheimer-like tau phosphorylation in normal rat brains. FEBS Lett 586, 3737-7345.

[36] Zhu D, Shi J, Zhang Y, Wang B, Liu W, Chen Z, Tong Q (2011) Central angiotensin II stimulation promotes $\beta$ amyloid production in Sprague Dawley rats. PLoS One 6, e16037.

[37] Yamada K, Uchida S, Takahashi S, Takayama M, Nagata Y, Suzuki N, Shirakura S, Kanda T (2010) Effect of a centrally active angiotensin-converting enzyme inhibitor, perindopril, on cognitive performance in a mouse model of Alzheimer's disease. Brain Res 1352, 176-186.

[38] Yamada K, Horita T, Takayama M, Takahashi S, Takaba K, Nagata Y, Suzuki N, Kanda T (2011) Effect of a centrally active angiotensin converting enzyme inhibitor, perindopril, on cognitive performance in chronic cerebral hypo-perfusion rats. Brain Res 1421, 110-120.

[39] Dong YF, Kataoka K, Tokutomi Y, Nako H, Nakamura T, Toyama K, Sueta D, Koibuchi N, Yamamoto E, Ogawa H, Kim-Mitsuyama S (2011) Perindopril, a centrally active angiotensin-converting enzyme inhibitor, prevents cognitive impairment in mouse models of Alzheimer's disease. FASEB J 25, 2911-2920.

[40] Tota S, Nath C, Najmi AK, Shukla R, Hanif K (2012) Inhibition of central angiotensin converting enzyme ameliorates scopolamine induced memory impairment in mice: Role of cholinergic neurotransmission, cerebral blood flow and brain energy metabolism. Behav Brain Res 232, 66-76.

[41] Ferrington L, Palmer LE, Love S, Horsburgh KJ, Kelly PA, Kehoe PG (2012) Angiotensin II-inhibition: effect on Alzheimer's pathology in the aged triple transgenic mouse. Am J Transl Res 4, 151-164.

[42] Teo K, Yusuf S, Sleight P, Anderson C, Mookadam F, Ramos B, Hilbrich L, Pogue J, Schumacher H, ONTARGET/TRANSCEND Investigators (2004) Rationale, design, and baseline characteristics of 2 large, simple, randomized trials evaluating telmisartan, ramipril, and their combination in high-risk patients: the Ongoing Telmisartan Alone and in Combination with Ramipril Global Endpoint Trial/Telmisartan Randomized Assessment Study in ACE Intolerant Patients with Cardiovascular Disease (ONTARGET/TRANSCEND) trials. Am Heart J 148, 52-61.

[43] Lithell H, Hansson L, Skoog I, Elmfeldt D, Hofman A, Olofsson B, Trenkwalder P, Zanchetti A, SCOPE Study Group (2003) The Study on Cognition and Prognosis in the Elderly (SCOPE): principal results of a randomized double-blind intervention trial. J Hypertens 21, 875-886.

[44] Wharton W, Stein JH, Korcarz C, Sachs J, Olson SR, Zetterberg $\mathrm{H}$, Dowling $\mathrm{M}$, Ye S, Gleason CE, Underbakke G, Jacobson LE, Johnson SC, Sager MA, Asthana S, Carlsson CM (2012) The effects of ramipril in individuals at risk for Alzheimer's disease: results of a pilot clinical trial. J Alzheimers Dis 32, 147-156.

[45] Rosenberg P, Mielke M, Tschanz J, Cook L, Corcoran C, Hayden KM, Norton M, Rabins PV, Green RC, Welsh-Bohmer KA, Breitner JCS, Munger R, Lyketsos CG (2008) Effects of cardiovascular medications on rate of functional decline in Alzheimer disease. Am J Geriatric Psychiatry 16, 883-892.

[46] Sumukadas D, Witham MD, Struthers AD, McMurdo MET (2007) Effect of perindopril on physical function in elderly people with functional impairment: a randomized controlled trial. CMAJ 177, 867-874.

[47] Wong AKW, Lord SR, Sturnieks DL, Delbaere K, Trollor JN, Close JCT (2013) Angiotensin system-blocking medications are associated with fewer falls over 12 months in communitydwelling older people. J Am Geriatr Soc 61, 776-781.

[48] Regan C, Katona C, Walker Z, Hooper J, Donovan J, Livingston $\mathrm{G}$ (2006) Relationship of vascular risk to the progression of Alzheimer disease. Neurology 67, 1357-1362.

[49] Seripa D, Paroni G, Matera MG, Gravina C, Scarcelli C, Corritore M, D'Ambrosio LP, Urbano M, D'Onofrio G, Copetti M, Kehoe PG, Panza F, Pilotto A (2011) Angiotensin-converting enzyme (ACE) genotypes and disability in hospitalized older patients. Age (Dordr) 33, 409-419.

[50] Kritchevsky SB, Nicklas BJ, Visser M, Simonsick EM, Newman AB, Harris TB, Lange EM, Penninx BW, Goodpaster BH, Satterfield S, Colbert LH, Rubin SM, Pahor M (2005) Angiotensin-converting enzyme insertion/deletion genotype, exercise, and physical decline. JAMA 294, 691-698.

[51] Gard PR (2004) Angiotensin as a target for the treatment of Alzheimer's disease, anxiety and depression. Expert Opin Ther Targets 8, 7-14.

[52] Braszko JJ, Karwowska-Polecka W, Halicka D, Gard PR (2003) Captopril and enalapril improve cognition and depressed mood in hypertensive patients. J Basic Clin Physiol Pharmacol 14, 323-343.

[53] Deary IJ, Capewell S, Hajducka C, Muir AL (1991) The effects of captopril vs atenolol on memory, information processing and mood: a double-blind crossover study. Br J Clin Pharmacol 32, 347-353. 
[54] Rogers D, Pies R (2008) General medical drugs associated with depression. Psychiatry (Edgmont) 5, 28.

[55] Molloy DW, Standish TI, Zhou Q, Guyatt G (2013) A multi-centre, blinded, randomized, factorial controlled trial of doxycycline and rifampin for treatment of Alzheimer's disease: the DARAD trial. Int J Geriatr Psychiatry 28, 463-470.

[56] Standish TI, Molloy DW, Bédard M, Layne EC, Murray EA, Strang D (1996) Improved reliability of the Standardized Alzheimer's Disease Assessment Scale (SADAS) compared with the Alzheimer's Disease Assessment Scale (ADAS). $J$ Am Geriatr Soc 44, 712-716.

[57] Schafer KA, Tractenberg RE, Sano M, Mackell JA, Thomas RG, Gamst A, Thal LJ, Morris JC, Alzheimer's Disease Cooperative, Study (2004) Reliability of monitoring the Clinical Dementia Rating in multicenter clinical trials. Alzheimer Dis Assoc Disord 18, 219-222.

[58] Molloy DW, Alemayehu E, Roberts RS (1991) Reliability of a standardized mini-mental state examination compared with the traditional mini-mental state examination. Am J Psychiatry 148, 102-105.

[59] Molloy DW, Standish TIM (1997) A guide to the standardized mini-mental state examination. Int Psychogeriatrics 9, 87-94.

[60] O'Caoimh R, Gao Y, McGlade C, Healy L, Gallagher P, Timmons S, Molloy DW (2012) Comparison of the quick mild cognitive impairment (Qmci) screen and the SMMSE in screening for mild cognitive impairment. Age Ageing 41, 624-629.

[61] O'Caoimh R, Gao Y, Gallagher P, Eustace J, McGlade C, Molloy DW (2013) Which part of the quick mild cognitive impairment screen $(\mathrm{Q} m c i)$ discriminates between normal cognition, mild cognitive impairment and dementia? Age Ageing 42, 324-330.

[62] O'Caoimh R, Svendrovski A, Johnston B, Gao Y, McGlade C, Timmons S, Eustace J, Guyatt G, Molloy DW (2014) The quick mild cognitive impairment screen correlated with the standardised Alzheimer's disease assessment scale-cognitive section in clinical trials. J Clin Epidemiol 67, 87-92.

[63] Yesavage JA (1988) Geriatric depression scale. Psychopharmacol Bull 24, 709-711.

[64] Alexopoulos GA, Abrams RC, Young RC, Shamoian CA (1988) Cornell scale for depression in dementia. Biol Psych 23, $271-284$

[65] Lawton MP, Brody EM (1969) Assessment of older people: self-maintaining and instrumental activities of daily living. Gerontologist 9, 179-186.

[66] Molloy DW, McIlroy WE, Guyatt GH, Lever JA (1991) Validity and reliability of the dysfunctional behavior rating instrument. Acta Psychiatr Scand 84, 103-106.

[67] Molloy DW, Bédard M, Guyatt GH, Lever JA (1996) Dysfunctional behaviour rating instrument. Int Psychogeriatr 8, 333-341.

[68] Rosen WG, Mohs RC, Davis KL (1984) A new rating scale for Alzheimer's disease. Am J Psychiatry 141, 1356-1364.

[69] Weyer G, Erzigkeit H, Kanowski S, Ihl R, Hadler D (1997) Alzheimer's Disease Assessment Scale: reliability and validity in a multicenter clinical trial. Int Psychogeriatrics 9, 123-138.

[70] Marc LG, Raue PJ, Bruce ML (2008) Screening performance of the geriatric depression scale (GDS-15) in a diverse elderly home care population. Am J Geriatr Psychiatry 16, 914-921.
[71] McKhann G, Drachman D, Folstein M, Katzman R, Price D, Stadlan EM (1984) Clinical diagnosis of Alzheimer's disease: report of the NINCDS-ADRDA Work Group under the auspices of Department of Health and Human Services Task Force on Alzheimer's Disease. Neurology 34, 939-944.

[72] Hanes DS, Weir MR (2007) Usefulness of ARBs and ACE inhibitors in the prevention of vascular dementia in the elderly. Am J Geriatr Cardiol 16, 175-182.

[73] Henriksen EJ, Jacob S (2003) Modulation of metabolic control by angiotensin converting enzyme (ACE) inhibition. J Cell Physiol 196, 171-179.

[74] Onder G, Penninx BW, Balkrishnan R, Fried LP, Chaves $\mathrm{PH}$, Williamson J, Carter C, Di Bari M, Guralnik JM, Pahor M (2002) Relation between use of angiotensin-converting enzyme inhibitors and muscle strength and physical function in older women: an observational study. Lancet 359, 926-930.

[75] Montgomery H, Clarkson P, Barnard M, Bell J, Brynes A, Dollery C, Hajnal J, Hemingway H, Mercer D, Jarman P, Marshall R, Prasad K, Rayson M, Saeed N, Talmud P, Thomas L, Jubb M, World M, Humphries S (1999) Angiotensinconverting-enzyme gene insertion/deletion polymorphism and response to physical training. Lancet 353, 541-545.

[76] Tollefson GD (1990) Short-term effects of the calcium channel blocker nimodipine (Bay-e-9736) in the management of primary degenerative dementia. Biol Psychiatry 27, 11331142.

[77] Kennelly S, Abdullah L, Kenny RA, Mathura V, Luis CA, Mouzon B, Crawford F, Mullan M, Lawlor B (2012) Apolipoprotein E genotype-specific short-term cognitive benefits of treatment with the antihypertensive nilvadipine in Alzheimer's patients - an open label trial. Int J Geriatr Psychiatry 27, 415-422.

[78] Cesari M, Pedone C, Incalzi RA, Pahor M (2010) ACE inhibition and physical function. results from the trial of angiotensin converting enzyme inhibition and novel cardiovascular risk factors (TRAIN) study. J Am Med Dir Assoc 11, 26.

[79] Hutcheon SD, Gillespie ND, Crombie IK, Struthers AD, McMurdo ME (2002) Perindopril improves six minute walking distance in older patients with left ventricular systolic dysfunction: a randomised double blind placebo controlled trial. Heart 88, 373-377.

[80] Zi M, Carmichael N, Lye M (2003) The effect of quinapril on functional status of elderly patients with diastolic heart failure. Cardiovasc Drugs Ther 17, 133-139.

[81] Cleland JG, Tendera M, Adamus J, Freemantle N, Polonski L, Taylor J (2006) The perindopril in elderly people with chronic heart failure (PEP-CHF) study. Eur Heart J 27, 2338-2345.

[82] Chapman RH, Benner JS, Petrilla AA, Tierce JC, Collins SR, Battleman DS, Schwartz JS (2005) Predictors of adherence with antihypertensive and lipid-lowering therapy. Arch Intern Med 165, 1147-1152.

[83] Conlin PR, Gerth WC, Fox J, Roehm JB, Boccuzzi SJ (2001) Four-year persistence patterns among patients initiating therapy with the angiotensin II receptor antagonist losartan versus other antihypertensive drug classes. Clin Ther 23, 1999-2010.

[84] Sheehan B (2012) Assessment scales in dementia. Ther Adv Neurol Disord 5, 349-358. 